\title{
O ENSINO DA TEMÁTICA AMBIENTAL NAS INSTITUIÇÕES DE ENSINO SUPERIOR NO BRASIL
}

\author{
Maria Teresa Ribeiro ${ }^{1}$ \\ Anne Caroline Malvestio²
}

Resumo: Reconhecendo a importância da inserção da temática ambiental no ensino e a relevância das Instituições de Ensino Superior (IES) para a formação em Educação Ambiental (EA), este trabalho teve por objetivo avaliar, a partir de revisão bibliográfica, em que medida a discussão de questões ambientais e a EA têm sido inseridas nos cursos de ensino superior no Brasil e quais os desafios que têm sido enfrentados. Através da revisão foi possível identificar que a inserção do tema ainda não se efetivou em diversos cursos superiores e que tanto a inserção do tema no currículo quanto a prática da EA nos contextos em que já está inserida enfrentam dificuldades, em especial para a prática da interdisciplinaridade e prática a partir de abordagem crítica.

Palavras-chave: Educação Ambiental; Ensino Superior; Meio Ambiente; Instituição de Ensino Superior.

Abstract: Considering the importance of introducing the environmental subject in education and the relevance of Higher Education Institutions for Environmental Education (EE), this paper aims to assess to what extent environmental issues and EE has been included in higher education curriculum in Brazil and what challenges have been faced. Based on literature review, it was possible to identify that the introduction of this theme in higher education is yet not a reality in many courses. Moreover, both the attempts to include environmental issues in the curriculum and the EE practice face difficulties, specially regarding interdisciplinarity and the practice based on a critical approach.

Keywords: Environmental Education; Higher Education; Environment; Higher Education Institution.

\footnotetext{
1 Universidade Federal de Uberlândia. E-mail: 42teresamaria@gmail.com. Link para o Lattes: http://lattes.cnpq.br/4426931706759348

2 Universidade Federal de Uberlândia. E-mail: anne.malvestio@ufu.br. Link para o Lattes: http://lattes.cnpq.br/1065150818917992
} 


\section{Introdução}

A problemática ambiental é definida por Fernandes e Sampaio, (2008, p. 89), como, "Uma problemática eminentemente social que surge da forma como a sociedade se relaciona com a natureza". Neste contexto, o desequilíbrio social e o desequilíbrio ambiental são intrinsicamente associados e têm uma origem em comum: a racionalidade predominantemente econômica, relacionada às formas de consumo excessivo de recursos naturais e geração de resíduos de nossa sociedade. Então, para a construção de um novo patamar societário, de existência integrada às demais espécies vivas e em conformidade com o mundo, é preciso superar as formas de alienação que levam a desagregação entre sociedade humana e natureza (LOUREIRO, 2004).

De acordo com Jacobi (2003, p. 190), nesse quadro, a Educação Ambiental (EA) é estratégica, sendo que:

A reflexão sobre as práticas sociais, em um contexto marcado pela degradação permanente do meio ambiente e seus ecossistemas, envolve uma necessária articulação com a produção de sentidos sobre a Educação Ambiental.

A Educação Ambiental é referenciada na legislação brasileira. A Lei no 6.938 de 1981, que dispõe sobre a Política Nacional do Meio Ambiente (PNMA), em seu artigo $2^{\circ}$, inciso $X$, estabelece como um de seus princípios que a "Educação Ambiental dever ser ministrada a todos os níveis de ensino, objetivando a participação ativa na defesa do meio ambiente" (BRASIL, 1981). Já a Lei no 9.795 de 1999, que institui a Política Nacional de Educação Ambiental (PNEA), em seu artigo $2^{\circ}$, estabelece que "A Educação Ambiental é um componente essencial e permanente da educação nacional, devendo estar presente, de forma articulada, em todos os níveis e modalidades do processo educativo, em caráter formal e não-formal' (BRASIL, 1999).

Nesse sentido, Instituições de Ensino Superior (IES), estando no papel de centros de educação técnica/superior, são núcleos importantes para a formação em EA e, portanto, devem assumir responsabilidade no processo de incorporar a dimensão ambiental nos sistemas de educação e formação profissional (MORALES, 2007).

Souza e Andrade (2014, p. 4118) afirmam que a formação profissional deve estar associada à formação de cidadãos:

Formar profissionais capazes de criticar, refletir e propor alternativas e estratégias para solução e minimização de problemas vivenciados pela sociedade não deve estar dissociado de formar cidadãos. Promover uma educação efetiva diante das necessidades sociais, ambientais, culturais, de saúde, é mais do que uma das funções da universidade, perpassa a necessidade e o direito à qualidade de vida que é reafirmada a cada discussão sobre educação.

Revbea, São Paulo, V. 16, № 3: 347-361, 2021. 
Reconhecendo, então, a importância da inserção da temática ambiental no ensino superior, este trabalho teve por objetivo avaliar, a partir de revisão bibliográfica, em que medida a discussão de questões ambientais e a Educação Ambiental têm sido inseridas nos cursos de ensino superior, bem como quais os desafios que têm sido enfrentados.

\section{Metodologia}

O trabalho foi desenvolvido através de revisão bibliográfica sistemática, por meio da qual buscou-se contextualizar a EA no ensino superior, respondendo às perguntas: "Em que medida a discussão de questões ambientais e a Educação Ambiental têm sido inseridas nos cursos de ensino superior?" e "Quais as dificuldades enfrentadas para essa inserção?". Para isso, utilizou-se como ferramenta de pesquisa a base online de artigos científicos "SciELO". As palavras-chave inseridas para a busca de artigos foram: educação, ambiental, ensino, superior, selecionando "Todos os Índices" no campo de pesquisa. A busca foi realizada em 09 de março de 2020 e foram identificados 22 artigos científicos, para o período de 2014 a 2019.

$\mathrm{Na}$ sequência, para verificar se os artigos identificados abordavam as perguntas que guiaram essa pesquisa, primeiro foram avaliados os títulos dos artigos e, em seguida, seus resumos. Com isso, 13 artigos foram selecionados para a presente revisão bibliográfica. Todos eles foram lidos integralmente e, a partir de seus conteúdos, buscou-se responder às perguntas-guia dessa revisão bibliográfica. A versão lida foi sempre a versão na língua portuguesa.

Os 13 artigos analisados são de diferentes autores e estão distribuídos em 11 revistas acadêmicas, sendo elas: Ciência \& Educação (Bauru) (2 artigos); Actualidades Investigativas en Educación (1 artigo); Da Investigação as Práticas (1 artigo); Revista Brasileira de Educação (1 artigo); Revista Brasileira de Educação Física e Esporte (1 artigo); Revista Eletrônica de Administração (Porto Alegre) (1 artigo); Tecné, Episteme y Didaxis: TED (1 artigo); Revista Gaúcha de Enfermagem (1 artigo); Ciência \& Saúde Coletiva (1 artigo); Revista Internacional de Investigación en Ciencias Sociales (1 artigo) e Educar em Revista (2 artigos). Dos 13 artigos, quatro foram publicados em 2014, quatro em 2015, um em 2016, dois em 2017 e dois em 2019.

\section{Contextualizando a Educação Ambiental}

A Constituição Federal de 1988 atribui à sociedade o dever de proteger - meio ambiente e à educação a responsabilidade pela formação da consciência crítica e ambiental da sociedade. Assim, a inserção da Educação Ambiental no contexto escolar é uma forma de realizar tal proposição (BOTELHO; COUTO; MASI, 2014). De acordo com Souza (2016), em meio a um contexto em que a educação vem sendo mercantilizada - pelo mesmo sistema que mercantiliza a natureza, promove competição, incentiva a apropriação dos recursos naturais e desvaloriza a vida - a EA surge como

revista brasileira educação ambiental 
parte de uma proposta que busca soluções para os problemas ambientais e mudanças dos paradigmas da sociedade atual.

Já Henning (2019) afirma que o campo de estudos da EA não pode ficar indiferente às nossas marcas históricas. A autora faz uma análise dos fundamentos da EA, considerando em que medida o discurso inicial da ciência moderna pode ser entendido como uma das condições de possibilidade para emergência da crise ambiental. De acordo com a autora, o ser humano moderno, na busca por progresso e melhoria de suas condições de vida, objetificou a natureza e tornou-a espaço de sua apropriação.

Essa forma de interferência, estabelecida entre o desenvolvimento antrópico e o funcionamento natural dos ecossistemas, foi norteada pela cosmovisão mecanicista, que gerou uma ideia de possível separação entre os domínios social e natural, sob a perspectiva de dominação do primeiro sobre o segundo (ROTA; BATISTELA; FERREIRA, 2017). A imponência do saber e a lógica cartesiana passaram a explicar o mundo e agir sobre ele, sendo a natureza um dos objetos dominados (HENNING, 2019). A cultura técnicocientífico, fundamentada pela racionalidade instrumental, econômica, capitalista-industrial e tecnológica, pretendeu reduzir a complexidade da realidade e dos sistemas naturais através do determinismo e do mecanicismo dos fenômenos físicos e naturais. É uma cultura que corresponde à fragmentação e à coisificação do mundo em função da busca do seu controle (TEIXEIRA e TORALES, 2014).

Em contraponto a essas correntes, há outras que compreendem a educação como uma possibilidade de caminho para a compreensão e construção da realidade em sua complexidade. Conforme Tozoni-Reis e Campos (2014, p. 150),

[...] a educação tem como objetivo realizar a tarefa de formação humana, através de um processo de conscientização que significa conhecer e interpretar a realidade e atuar sobre ela, construindo-a [...] o processo de formação do ser humano é histórico e social, o que quer dizer intencionalmente dirigido, pelos próprios seres humanos em suas relações entre si e com o ambiente em que vivem.

A concepção crítica de educação busca propiciar condições para que os sujeitos possam fazer uso de seu próprio entendimento, pensar por si próprios, sem o direcionamento de outros, considerando a realidade da sociedade em que estão inseridos. Nesse sentido, a EA pode ser praticada com objetivo da formação de uma consciência crítica em relação ao meio ambiente (BOTELHO; COUTO; MASI, 2014).

Nesse contexto, a EA vem se constituindo como uma área em permanente construção, na reflexão crítica e complexa dos problemas decorrentes do confronto entre os elementos naturais e os antrópicos. É 
necessário um olhar criterioso sobre o que se entende por "meio ambiente" e a relação "ser humano e natureza" (MARTINS et al., 2015). Segundo Loureiro (2005, citado por Souza, 2016) as concepções da EA se dividem em dois grupos: um grupo denominado conservador e o outro chamado de crítico.

Conforme Souza (2016, p. 124),

A EA conservadora [...], tem como objetivo da educação mudanças comportamentais individuais sem considerar as relações sociais, dá pouca ênfase à problematização da realidade e processos históricos, foca na redução do consumo de bens naturais, sem discutir o modo de produção; tem pouco entendimento da relação homem-natureza; e dá-se de forma descontextualizada e despolitizada.

Por outro lado, a EA crítica (transformadora) busca autonomia e liberdade social, redefinindo a relação do ser humano com outras espécies e planeta, se dá de forma politizada e acredita na participação social e no exercício da cidadania, preocupa-se com o diálogo entre diferentes ciências e cultura popular (LOUREIRO, 2005, citado por SOUZA, 2016).

A prática de uma EA de caráter crítico prevê a autonomia dos sujeitos, a libertação de padrões que levam a desigualdades sociais e à degradação ambiental, e busca redefinir a relação do ser humano com o meio ambiente. Para isso, promove o diálogo entre diversas áreas do saber, na busca por soluções para os diversos problemas que a sociedade enfrenta e que são consequências de um tipo de comportamento humano que tem sido, historicamente, autodestrutivo.

Dado que a inserção e prática da EA nas diferentes modalidades (formal e não formal) de ensino no Brasil ainda é incipiente, em especial tendo em vista a velocidade da degradação ambiental, Martins e colaboradores (2015) destacam a necessidade do desenvolvimento de um "saber ambiental", em que os diferentes saberes das áreas das ciências naturais, humanas e exatas sejam tratados de forma articulada e que capacite cidadãos para o desenvolvimento de ações sustentáveis, nas diferentes práticas profissionais e sociais, mediante o envolvimento individual e coletivo, abarcando as esferas pública, privada e a sociedade civil em geral.

\section{A Educação Ambiental no ensino superior no Brasil}

O conhecimento ambiental está presente nas universidades brasileiras desde o final dos anos 1980 e está inserido no ensino, na pesquisa, na extensão e na gestão, tanto em nível de graduação quanto de pós-graduação, através de diferentes abordagens teóricas e metodológicas. No entanto, apesar de estar presente nas IES, a temática ambiental ainda encontra dificuldades para ser, de fato, inserida de forma mais ampla nos currículos e práticas das Universidades. Por exemplo, ao propor (e demandar) abordagem 
interdisciplinar, o ensino do tema tem como desafio a própria organização do conhecimento no ensino superior em unidades, departamentos e disciplinas que dividem e sistematizam os saberes (TEIXEIRA; TORALES, 2014).

Souza (2016) apresenta em seu trabalho um levantamento dos diversos cursos de graduação voltados para a área ambiental nas IES públicas brasileiras e discute a inserção das questões ambientais nessas instituições, refletindo sobre as dificuldades e desafios a serem superados por elas na busca por soluções à crise socioambiental. São diversas as abordagens práticas e teóricas possíveis da EA e a questão educacional pode ser conduzida de forma libertadora ou opressora, dependendo das concepções dos grupos que dividem e disputam esse campo.

Assim, Souza (2016) propõe uma reflexão sobre como a inserção de empresas privadas nas IES públicas e nos cursos voltados para a área ambiental, principalmente com financiamentos de projetos e pesquisas, pode tornar prioritária a produção de conhecimentos voltados para o mercado, o que afasta as IES de seu papel também social. Segundo a autora, essa situação resulta em cursos, relacionados à área de meio ambiente, que não incorporam a questão ambiental de forma crítica e reflexiva e que têm propostas educacionais que enfatizam aspectos técnicos/biológicos em detrimento das dimensões políticas/éticas das questões ambientais.

No que se refere à inserção da EA nos Projetos Pedagógicos dos cursos, segundo Botelho, Couto e Masi (2014), a EA ainda não é postulada como obrigatória nos currículos de muitos cursos do ensino superior. No entanto, para esses autores, considerando-se as características e objetivos da $E A$, esta deveria avançar para uma situação de obrigatoriedade em todos os cursos de educação superior, a fim de possibilitar maior compromisso políticosocial, de modo a atender a espacialização temática (que pode ser entendida como as diversas abordagens do tema de acordo com cada área do conhecimento) e a espacialização de conhecimentos e saberes ambientais em todas as áreas (que trata do nível de aprofundamento que será dado a determinado tema). Nesse sentido, os autores consideram o estudo obrigatório do meio ambiente como componente fundamental para garantir a sadia qualidade de vida e o equilíbrio ambiental.

Quanto à abordagem de EA adotada, Sousa Filho et al. (2015) afirmam que a EA ainda é tratada nas IES de maneira conservadora e limitada, sendo praticada em ações pontuais (coleta seletiva, por exemplo). Aspecto este que é limitante para a prática da $E A$, pois não contribui para que ela atinja camadas mais profundas do comportamento social, gerando mudanças coletivas. Vale ressaltar, no entanto, que o cenário socioambiental de nossa sociedade nos desafia a pensar em formas de lidar com os diversos problemas ambientais que nos afligem e que são indissociáveis dos vários problemas sociais (COSTA, 2016). Assim, uma argumentação consistente e o desenvolvimento de pesquisas sobre o conhecimento ambiental são cada vez mais necessárias como parte da formação dos futuros profissionais de nível superior. 
Nesse sentido, Teixeira e Torales (2014) analisam de que maneira os cursos de licenciatura estão preparando os futuros professores para a institucionalização da EA, através de uma pesquisa exploratória sobre ações formativas que abordam a dimensão ambiental nos cursos de licenciatura da Universidade Federal do Paraná (UFPR). As autoras observam que, naquela instituição, a inserção de disciplinas que tratam da EA ocorre em apenas alguns cursos de licenciatura (minoria) e que a presença da temática ambiental é mais expressiva em cursos de bacharelado.

Já Sousa Filho et al. (2015), buscando investigar as variáveis explicativas do comportamento ecológico de estudantes de bacharelado em Administração, observaram que nesse curso é predominante uma EA orientada para a gestão, ou seja, a EA não é ofertada enquanto disciplina, de forma a valorizar o tema, e sim colocada dentro de disciplinas que focam na gestão ou na responsabilidade social empresarial.

Tozoni-Reis e Campos (2014) também abordam, em seu estudo, como a formação de professores no ensino superior reflete sobre a abordagem dada à EA na educação básica. Partindo de uma concepção crítica e transformadora da escola na sociedade, as autoras problematizam a inserção da EA na educação escolar pensando nos currículos escolares como forma política de sua inserção. A inserção da EA, necessária para transformar sujeitos e realidades em crise, passa pela reformulação da formação de professores, na perspectiva de superar a racionalidade prática, investindo no seu protagonismo na construção e realização de um currículo escolar que garanta o tratamento de temas ambientais como atividades curriculares nas escolas, compreendidas como um espaço social institucional que tem como papel contribuir para a formação plena dos sujeitos (TOZONI-REIS; CAMPOS, 2014).

Também pôde ser observado nos artigos revisados (TEIXEIRA; TORALES, 2014; TOZONI-REIS; CAMPOS, 2014) que as disciplinas que abordam temas relacionados a meio ambiente e EA são muito diversas e tratam do tema a partir de diferentes abordagens. Assim, parece não haver consenso sobre o que se pretende ensinar/construir, tão pouco sobre o que seriam os elementos e métodos necessários para uma formação consistente. Essas características podem indicar uma frágil preparação para o efetivo desenvolvimento dessa temática no ensino superior.

Rotta, Batistela e Ferreira (2017) apresentam uma proposta de Ambientalização Educacional ou "Ambientalização dos Espaços Educativos Sustentáveis", em que propõem a articulação de currículos de cursos de graduação de licenciatura, bacharelado e tecnólogo, para inserir a questão ambiental em suas diversas dimensões, através da interdisciplinaridade. Os autores reforçam a necessidade de haver uma "cultura ambiental" nas universidades, que permita à própria comunidade universitária discutir metodologias e abordagens que viabilizem a ambientalização educacional nos currículos de cursos de graduação. 
Também abordando a ambientalização educacional, Rodrigues (2015) analisou evidências da ambientalização curricular em programas de educação física de Universidades Federais do Brasil, através de um estudo dos planos de ensino de disciplinas que abordam questões ambientais. Em seu levantamento teórico, o autor identificou como principal barreira da institucionalização da dimensão ambiental no ensino superior as dificuldades no processo de elaboração de uma base epistemológica, ou "lugares comuns" em que a EA possa se situar, o que dificulta sua atuação mais consistente, para além das práticas pontuais. Souza (2016) também aponta para a necessidade desse elo epistemológico que inclua a EA no ensino superior.

O fato de a inserção do campo ambiental como área de conhecimento ser recente é considerado como um dos motivos da complexidade e diversidade de compreensões associadas à sua discussão, que resulta em uma área de conhecimento ainda pouco conclusiva (RODRIGUES, 2015; SOUZA, 2016). Além disso, tendo em vista seu caráter interdisciplinar, a discussão sobre EA requer um olhar sobre as complexas conexões que unem áreas do conhecimento profundamente vinculadas. No entanto, devido a cosmovisão mecanicista que fragmenta e sistematiza os saberes, essas conexões se perdem. Nesse sentido, recuperar vínculos que ligam diferentes áreas do saber pode ser uma estratégia eficaz para a superação dessa situação de crise ambiental.

De acordo com Botelho, Couto e Masi (2014, p. 85), a perspectiva da interdisciplinaridade

[...] considera que o conhecimento produzido por uma ciência em particular, apesar de sua especificidade, não é suficiente para resolver todos os problemas ambientais, ao contrário, a capacidade resolutiva deverá ser produto do conhecimento gerado pela associação teórica e metodológica das várias ciências. Assim, é pertinente observar que o campo ambiental abarca processos naturais e sociais diversos, exigindo dessa forma, a atuação de especializações diversas para sua interpretação e intervenção [...]

A saúde humana, sob essa perspectiva da interdisciplinaridade, é um exemplo de ciência que é vinculada com diversas outras áreas, tendo uma relação muito estreita com a qualidade do meio ambiente e relações estabelecidas entre sociedade e o meio. Nesse sentido, Peres et al. (2015) exploram a relação entre saúde e sustentabilidade ambiental, considerando que o processo saúde-doença está diretamente relacionado com o meio ambiente. Os autores buscam descrever a percepção de enfermeiros docentes sobre a EA e sua relação com esta formação profissional (enfermagem). Os resultados evidenciam que a EA recebe pouco espaço na estrutura curricular da formação em enfermagem, ou é vinculada às disciplinas de saneamento do meio. A conclusão salienta a necessidade de uma maior abordagem sobre o 
tema e a importância de se incorporar a perspectiva socioambiental nos cuidados à saúde.

Souza e Andrade (2014) também buscaram analisar a interdisciplinaridade entre saúde e meio ambiente. Os dados da pesquisa foram coletados em programas e ementas de disciplinas de 17 cursos de graduação na área de Saúde, em quatro universidades estaduais da Bahia. Os resultados apontaram que muitos cursos apresentavam componentes curriculares que abordavam a discussão interdisciplinar entre Saúde e Meio Ambiente, destacando-se o componente curricular de Saúde Coletiva.

As mesmas autoras também sinalizam para a relação estreita entre saúde e desenvolvimento, alertando que tanto o desenvolvimento insuficiente pode conduzir à pobreza, como o desenvolvimento inadequado pode levar ao consumo excessivo. Ambos têm consequências sobre as pessoas e o meio em que vivem. A própria assistência à saúde e seu ambiente de ensino são constantes produtores de resíduos de elevado risco que, se gerenciados de forma inadequada, são contaminantes potenciais do meio ambiente (SOUZA; ANDRADE, 2014). Nesse contexto, reforça-se a necessidade da abordagem interdisciplinar.

A interdisciplinaridade também foi tema abordado por Silva e Santos Junior (2019), que relataram experiência explorando a importância e a possibilidade de integração interdisciplinar, a partir de conteúdos relacionados à $E A$, entre as escolas do ensino básico e as universidades da região do Vale do São Francisco. O objetivo dos autores foi analisar como se dá a contextualização das temáticas ambientais nos currículos desses espaços institucionais, por meio de análise de livros didáticos (ensino básico) e artigos/livros científicos (ensino superior) e compreender se há uma conexão ou distanciamento entre eles. Os autores identificaram uma gama de objetivos que estão integrados entre as duas unidades de ensino e afirmaram que há uma significativa relação entre os conteúdos abordados no ensino básico e superior. No ensino básico as questões ambientais são organizadas em classes de disciplinas e na universidade é possibilitada uma visão mais explícita e integradora (portanto, mais interdisciplinar), o que facilita a difusão dos temas ligados à EA e representa uma complementariedade no estudo deste assunto ao longo da vida acadêmica de estudantes. No entanto, os autores apontam para a necessidade de uma boa articulação/mediação dos educadores para um melhor aproveitamento desses conteúdos.

Já Martins et al. (2015) descrevem uma proposta didática para a disciplina de Educação Ambiental de um curso de Ciências Biológicas de uma universidade pública brasileira, que foi construída a partir da discussão sobre as concepções dos alunos acerca do tema "meio ambiente". O intuito das autoras foi de compreender os conteúdos necessários à construção de um "saber" e um "fazer" mais reflexivo sobre as temáticas ambientais. Os discentes que participaram da pesquisa expressaram suas concepções sobre o tema a partir da questão: "Para você, o que é meio ambiente?". 
Os resultados expressaram que a formação anterior dos estudantes pode ter sido um fator relevante na explicitação de suas respostas. Esse questionamento e as respostas obtidas serviram de embasamento para 0 planejamento da abordagem da disciplina de EA, de forma a trabalhar uma possível desconstrução de visões reducionistas sobre o tema, propiciando a formação de estudantes mais reflexivos no que tange às questões ambientais. Com essa abordagem, Martins et al. (2015) oportunizaram aos estudantes envolvidos na pesquisa, futuros biólogos, um processo de ensinoaprendizagem interdisciplinar, que abordou múltiplas linguagens e teve como ponto de partida as próprias reflexões dos alunos. Dessa forma, a proposta pedagógica foi direcionada para trabalhar com a realidade do seu público-alvo.

Costa (2016) abordou uma discussão sobre a importância de desenvolver nos estudantes conhecimentos e práticas para que estes se tornem pessoas/profissionais que pensem por si e compreendam o que os rodeia, sendo capazes de intervir na resolução de problemas da comunidade e assumir um posicionamento crítico e ativo enquanto cidadãos. Nesse sentido, Costa (2016) discutiu a necessária mudança das práticas pedagógicas para promoção de um ensino focado nos estudantes e a importância de intervenções sociopolíticas como estratégia para a abordagem pedagógica construtiva. Assim, o autor apresentou os resultados obtidos na implementação do projeto "We act", na Escola Superior de Educação Jean Piaget de Almada e na unidade curricular de Atelier e Didática das Ciências e Educação Ambiental, para alunos do curso de Licenciatura em Educação Básica. Nesse projeto, os discentes foram desafiados a realizar uma intervenção socioambiental/sociocientífica em diferentes comunidades, visando a resolução das problemáticas encontradas e tendo em vista a melhoria da qualidade de vida e sustentabilidade naqueles locais. Os resultados obtidos evidenciaram que o envolvimento dos discentes nas ações com a comunidade impactaram suas concepções e atitudes (enquanto cidadãos e futuros educadores), melhorando suas competências docentes, e reforçando a importância da ciência para o cotidiano e para a resolução de problemas socioambientais (COSTA, 2016).

Assim, de maneira geral, os artigos revisados reforçam a necessidade e importância da adequada inserção da temática ambiental nos diversos cursos de ensino superior, conforme enunciado, por exemplo, por Souza (2016, p. 139)

A educação para o meio ambiente dentro das IES precisa buscar o equilíbrio entre a qualificação profissional para o trabalho e a formação do cidadão consciente de seus direitos e deveres para com a sociedade, pois tanto o mercado precisa de profissionais cada vez mais qualificados na área ambiental como a sociedade como um todo precisa que esses profissionais sejam bem formados e que se insiram nela como cidadãos críticos em busca do bem comum e da justiça socioambiental. 


\section{Desafios para a inserção das questões ambientais no ensino superior}

As dificuldades na adoção de práticas de proteção ambiental tornam a educação uma ferramenta imprescindível para a sensibilização das pessoas (SOUZA; ANDRADE, 2014). Apesar disso, as ações ambientais realizadas dentro das IES ainda são consideradas pontuais e pouco expressivas, sendo a crença no tecnicismo predominante (SOUZA, 2016). Nesse contexto, a EA continua sendo indispensável, sendo uma ferramenta para a geração de conhecimento e que pode possibilitar a fundamentação e o embasamento teórico para que práticas de proteção ambiental sejam adotadas, aprimoradas e contínuas a longo prazo.

Além disso, os artigos revisados apontam que o ensino fragmentado, dividido em disciplinas, tem se mostrado insuficiente para a busca de soluções dos problemas transversais, multidimensionais e globais que afligem o planeta. Essas evidências estão alinhadas ao que foi apontado por Morin ainda em 2003 (MORIN, 2003), indicando que nas últimas duas décadas se avançou pouco no sentido de superar tais dificuldades. Vale destacar que esse saber compartimentado dificulta o entendimento dos conjuntos complexos, das interações entre as partes e o todo. É, portanto um desafio que a educação enfrenta ao tratar das questões ambientais, que são dinâmicas, envolvem os ecossistemas e suas relações e que, portanto, devem ser analisadas em toda sua complexidade.

Botelho, Couto e Masi (2014, p. 79) atentam que "[...] a integração de uma nova temática de estudo no currículo escolar gera sempre tensões epistemológicas e disciplinares[...]". Assim, apesar do avanço na produção de conhecimentos no campo ambiental, a EA ainda enfrenta dificuldades de se institucionalizar no contexto do ensino superior e, segundo Rodrigues (2014), o principal entrave que leva a essa dificuldade é que o processo de formação de uma base epistemológica para o desenvolvimento do campo ambiental, especialmente considerando seu caráter transversal e interdisciplinar, é complexo e ainda emergente.

Conforme Botelho, Couto e Masi (2014, p. 89),

A inserção de saberes, ainda em ascensão, implica na reorganização das estruturas políticas, administrativas, acadêmicas e sociais. Assim, ao pensar uma nova temática de estudo, é preciso considerar, sobretudo, sua historicidade, sua relevância na produção de conhecimentos, na discussão e análise de questões político-social.

Outro importante desafio para a EA no ensino superior está relacionado à mercantilização do ensino superior. Como afirma Souza (2016, p. 125), 
[...] a educação passou a ter um papel estratégico para o projeto neoliberal. Os governos liberais passaram a intervir no sistema educacional juntamente com as empresas privadas, direcionando a formação para atender aos objetivos unicamente do mercado [...].

O processo de mercantilização da educação já está em curso no Brasil há décadas, situação induzida, principalmente, por uma crise financeira que resulta, por exemplo, na intensificação da privatização, diminuição de políticas e investimentos públicos nas universidades e currículos que visam apenas atender demandas do mercado (SANTOS, 2004; AGAPITO, 2016). Como consequência desse processo, Santos (2004) destacava a ascensão de uma crise institucional, resultante da contradição entre a autonomia das instituições universitárias em definir seus valores, objetivos e práticas, e a crescente pressão externa que as submete a padrões de eficácia e produtividade empresarial. A autonomia científica e pedagógica da universidade, que é possibilitada pelo suporte financeiro do Estado, fica ameaçada (SANTOS, 2004).

De acordo com Souza (2016, p. 132), esse contexto de produção de conhecimentos e formação profissional essencialmente voltados a seu valor no mercado representa um obstáculo à inserção da temática ambiental no ensino superior, que frequentemente fica restrita a "uma ligeira capacitação sobre problemas pontuais, nos quais a complexidade ambiental permanece reduzida e fragmentada". Como consequência, tem-se a formação de profissionais pouco capazes de refletir sobre os problemas socioambientais.

\section{Conclusões}

A revisão bibliográfica sistemática realizada permitiu identificar que, ao longo dos anos incluídos na pesquisa, o tema Educação Ambiental no ensino superior foi abordado em diferentes contextos e áreas do conhecimento. Neste estudo, foram revisados 13 artigos que exploraram este tema, discutindo-o de maneira geral ou nos contextos específicos de diferentes cursos, por exemplo, administração, ciências biológicas, enfermagem e licenciaturas diversas.

As situações retratadas evidenciam que, no contexto das IES brasileiras, a EA ainda não é obrigatória nos currículos de muitos cursos e encontra dificuldades para ser inserida. Além disso, as práticas existentes revelam uma diversidade de estratégias e abordagens em que a EA se apoia, evidenciando que não há uma única forma de Educação Ambiental, mas sim múltiplas educações ambientais, baseadas em diferentes concepções.

Pelo caráter interdisciplinar da EA e por ser um tema que deve ser tratado de acordo com a realidade onde está inserido, essa diversidade de possibilidades de práticas é esperada e, inclusive deve colaborar para a consolidação de uma base epistemológica em que a EA possa se situar. No entanto, cabe a reflexão sobre que abordagem de EA se pretende praticar e a 
partir de quais valores e com quais objetivos ela é trabalhada. Nesse sentido, a revisão realizada indica que, na prática do ensino superior, ainda parece haver a predominância da abordagem conservadora, apesar de a abordagem crítica ser recorrentemente recomendada, entendendo-a como mais apropriada para a formação de profissionais e cidadãos que sejam capazes de compreender, refletir e intervir em questões socioambientais.

A prática da EA crítica e da interdisciplinaridade, porém, esbarram em diversos obstáculos, sendo mais frequente a identificação de dificuldades em aplicá-las, do que o relato de experiências positivas em sua aplicação. Vale ressaltar, ainda, que o ensino da EA de concepção crítica esbarra na própria organização da sociedade, que tem como modelo de desenvolvimento econômico predominante o neoliberalismo, forma de organização social que reforça princípios de competitividade, individualismo, consumo, dominação, exploração e apropriação de recursos naturais, princípios que conduziram à atual situação de crise socioambiental.

Então, a partir da revisão bibliográfica sistemática realizada é possível perceber que a prática de uma Educação Ambiental que supere a obrigatoriedade curricular ainda é um desafio para as IES, o que passa pelas dificuldades de lidar com a interdisciplinaridade, de aplicar e manter práticas contínuas e de longo prazo, de praticar abordagens críticas e pelo processo de mercantilização do ensino superior.

Neste contexto, as IES Públicas têm um papel de destacada importância visto que, apesar do processo de mercantilização do ensino pelo qual vêm sendo pressionadas, têm autonomia pedagógica e científica, que é fundamental para se caminhar no sentido de inserir a temática ambiental de maneira adequada nos currículos, além de atuarem no ensino, na pesquisa e na extensão, nas diversas áreas do conhecimento.

Ressalta-se, por fim, que a busca por melhor qualidade ambiental e qualidade vida - acessível a toda a sociedade, requer melhor formação dos cidadãos e profissionais em relação à temática ambiental e, por isso, as Instituições de Ensino, de forma geral, e de Ensino Superior, em específico, têm o dever e o desafio de aprimorarem e amadurecerem suas práticas em relação à inserção da temática ambiental nas diversas áreas do conhecimento e espaços de atuação.

\section{Referências}

AGAPITO, A. P. F. Ensino superior no Brasil: expansão e mercantilização na contemporaneidade. Temporalis, v. 16, n. 32, p. 123-140, 2016.

BRASIL. Lei no 6938, de 31 de agosto de 1981. Dispõe sobre a Política Nacional do Meio Ambiente, seus fins e mecanismos de formulação e aplicação, e dá outras providências. Brasília, Disponível em: $<$ http://www.planalto.gov.br/ccivil 03/LEIS/L6938.htm>. Acesso em: 06 maio 2020.

revista brasileira educação ambiental 
BRASIL. Lei no 9795, de 27 de abril de 1999. Dispõe sobre a Educação Ambiental, institui a Política Nacional de Educação Ambiental e dá outras providências. Brasília. Disponível em: $<$ http://www.planalto.gov.br/ccivil 03/LEIS/L9795.htm>. Acesso em: 06 maio 2020.

BOTELHO, J. M. L; COUTO, B. do A.; MASI, S. D. Educação Ambiental e teoria crítica da educação: algumas considerações pertinentes. Rev. Int. Investig. Cienc. Soc., Assunção, v. 10, n. 1, p.75-90, jul. 2014.

COSTA, H. M. A educação em ciências e a intervenção sociopolítica em questões socioambientais e sociocientíficas: uma experiência na formação inicial de professores e educadores. Da Investigação às Práticas, Lisboa, v. 7, n. 2, p.72-92, jul. 2017.

FERNANDES, V.; SAMPAIO, C. A. C. Problemática ambiental ou problemática socioambiental? A natureza da relação sociedade/meio ambiente. Desenvolvimento e Meio Ambiente, UFPR, v. 18, n. 18, p.87-94, jul. 2008.

HENNING, P. C. Resistir ao presente: tensionando heranças modernas para pensar a Educação Ambiental. Ciência \& Educação (Bauru), v. 25, n. 3, p.763-781, set. 2019.

JACOBI, P. Educação Ambiental, cidadania e sustentabilidade. Cadernos de Pesquisa. N. 118, p.189-205, mar. 2003.

LOUREIRO, C. F. B. Educar, participar e transformar em Educação Ambiental. Rev. Brasileira de Educação Ambiental. Brasília: Rede Brasileira de Educação Ambiental. n. 0, p.13-20, nov. 2004.

MARTINS, G. A. et al. Uma proposta didática para disciplina de Educação Ambiental no Ensino Superior, a partir de concepções prévias sobre "meio ambiente". Rev. Fac. Cienc. Tecnol., Bogotá, n. 38, p. 57-74, set. 2015.

MORALES, A. G. M. O processo de formação em Educação Ambiental no ensino superior: trajetória dos cursos de especialização. Rev. Eletrônica do Mestrado em Educação Ambiental. v. 18, p.283-302, jan. 2007.

MORIN, E. A cabeça bem feita: repensar a reforma, reformar o pensamento. 8. ed. Rio de Janeiro: Bertrand, 2003. 128 p.

PERES, R. R.; CAMPONOGARA, S.; COSTA, V. Z. da; TERRA, M. G.; NIETSCHE, E. A. Educação Ambiental para docentes enfermeiros: percepção e relação com a formação do enfermeiro. Revista Gaúcha de Enfermagem, v. 36, p.85-93, 2015.

ROTTA, M.; BATISTELA, A. C.; FERREIRA, S. R. Ambientalização curricular no ensino superior: formação e sustentabilidade nos cursos de graduação. Actualidades Investigativas En Educación, v. 17, n. 2, p.1-20, 1 maio 2017. 
RODRIGUES, C. A ambientalização curricular de programas de Educação Física em universidades federais do Brasil. Revista Brasileira de Educação Física e Esporte, v. 29, n. 3, p.421-437, set. 2015.

SANTOS, B. de S. A Universidade do Século XXI: para uma reforma democrática e emancipatória da universidade. São Paulo: Cortez, 2004. 120 p.

SILVA, A. P.; SANTOS JUNIOR, R. P. dos. Educação Ambiental e sustentabilidade: é possível uma integração interdisciplinar entre o ensino básico e as universidades? Ciência \& Educação (Bauru), v. 25, n. 3, p.803814, set. 2019.

SOUSA FILHO, J. M. de; COIMBRA, D. B.; MESQUITA, R. F. de; LUNA, R. A. Análise do comportamento ecológico de estudantes de administração. Revista Eletrônica de Administração (porto Alegre), v. 21, n. 2, p.300-319, ago. 2015.

SOUZA, C. L. de; ANDRADE, C. S. Saúde, meio ambiente e território: uma discussão necessária na formação em saúde. Ciência \& Saúde Coletiva, v. 19, n. 10, p.4113-4122, out. 2014.

SOUZA, V. M. de. Para o mercado ou para a cidadania? A Educação Ambiental nas instituições públicas de ensino superior no Brasil. Revista Brasileira de Educação, v. 21, n. 64, p.121-142, mar. 2016.

TEIXEIRA, C.; TORALES, M. A. A questão ambiental e a formação de professores para a educação básica: um olhar sobre as licenciaturas: um olhar sobre as licenciaturas. Educar em Revista, n. 3, p. 127-144, 2014

TOZONI-REIS, M. F. de C.; CAMPOS, L. M. L. Educação Ambiental escolar, formação humana e formação de professores: articulações necessárias. Educar em Revista, n. 3, p. 145-162, 2014. 